\title{
Predicting Economic Performance of Bangladesh using Autoregressive Integrated Moving Average (ARIMA) model
}

\author{
Raad Mozib Lalon, $\mathrm{PhD}^{1}$ and Nusrat Jahan ${ }^{2}$
}

\begin{abstract}
This paper attempts to forecast the economic performance of Bangladesh measured with annual GDP data using an Autoregressive Integrated Moving Average (ARIMA) Model followed by test of goodness of fit using AIC (Akaike Information Criterion) and BIC (Bayesian Information Criterion) index value among six ARIMA models along with several diagnostic tests such as plotting ACF (Autocorrelation Function), PACF (Partial Autocorrelation Function) and performing Unit Root Test of the Residuals estimated by the selected forecasting ARIMA model. We have found the appropriate ARIMA $(1,0,1)$ model useful in predicting the GDP growth of Bangladesh for next couple of years adopting BoxJenkins approach to construct the ARIMA (p,r,q) model using the GDP data of Bangladesh provided in the World Bank Data stream from 1961 to 2019.
\end{abstract}

JEL classification numbers: B22, B23, C53.

Keywords: GDP growth, ACF, PACF, Stationary, ARIMA (p,r,q) model, Forecasting.

\footnotetext{
${ }^{1}$ Associate Professor, Department of Banking and Insurance, University of Dhaka.

2 Assistant Professor, Department of Business Administration, Uttara University.
}

Article Info: Received: December 29, 2020. Revised: January 14, 2021.

Published online: January 22, 2021. 


\section{Introduction}

GDP is the total monetary value of all finished services and goods produced within a country's borders in a specific time period. It is a crucial indicator of economic performance of a country. GDP is also considered as a weighty component in case of framing economic strategies.

Bangladesh ranked as the 39th largest economy in nominal terms, in the world, and 30th largest by purchasing power parity, in the year 2019. (Source: CIA World Fact Book). Ours is a developing market economy; there is a high potential that our country could possibly shed the "least developed country" status in near future. If we look back, the GDP growth of Bangladesh surpassed 7\% in FY2015-16 and was $7.11 \%$ percent. The GDP growth increased to $7.28 \%$ in FY2016-17 and 7.86\% in FY2017-18. The GDP growth was at 8.13\% as of FY2018-19. (Source: Bangladesh Bureau of Statistics).If we consider the role of individual sectors contributing in our economic growth we can easily find that agriculture, industry, manufacture, services sectors are crucial contributors. Though three fifths of Bangladeshis are engaged in the agriculture sector, three quarters of exports revenues came from RMG production, in the year of 2019. In 2019, the contribution of the GDP growth drivers in that year were; agricultural sector $9.13 \%$, industrial sector $17.61 \%$ manufacturing sector $19.28 \%$, and services sector $12.10 \%$.During 2019, the state of the Bangladesh economy arbitrated by the performance with reference to global, macro and micro levels, presents a mixed picture. GDP growth rate of Bangladesh may decline to $7.80 \%$ in the current fiscal year, i.e. 2020 from $8.10 \%$ in the previous fiscal year. Yet, the projected growth rate of Bangladesh is anticipated to be the highest in South Asia in 2020. (Source: Global Economy- the United Nations).

The rest of the paper is navigated as follows: section 2 discusses the review of relevant literatures of this study; section 3 mentions the objective of the paper contributing to the existing literatures; section 4 describes the methodology revealing the sample collection procedure, variables' identity and econometric models along with estimation procedure of the said models; section 5 reveals the empirical data and analysis with result followed by the discussion or findings on the results of this paper; Section 6 has concluded the findings of the paper.

\section{Literature Review}

GDP is considered as the significant parameter for assessing the national economic development and for anticipating the operating status of macro economy as a whole. The study concluded that GDP of Shaanxi was found to have an impressive upward trend. (Ning, W., Kuan-jiang, B., \& Zhi-fa., 2010).

Taking 20 African Countries as sample, some researchers tried to forecast future time series values. It was observed that upsurge in GDP growth will be noticed where the average rapidity of African economy in 1990-2030 will be of 5.52\%, and $\$ 2185.21$ billion to $\$ 10186.18$ billion GDP could be achieved. (Uwimana, A., Xiuchun, B., \& Shuguang, Z., 2018).

A study considered manufacturing firms of Bangladesh as sample. It was found that 
anticipated value of the manufacturing industries GDP divulges a sustainable increasing trend. (Bhuiyan, M. N. A., Ahmed, K. S., \& Jahan, R., 2008).

The methodology of Box- Jenkins applied for the period 1980-2013 with one ARIMA $(1,1,1)$ model was used for forecasting real GDP rate (of year 2015, 2016 and 2017) in Greece. Statistical results found that Greece's real GDP rate to be improving steadily. (Dritsaki, C., 2015).

A study tried to scrutinize the predicted GDP growth rate of India by using ARIMA $(1,2,2)$ model for time period of 60 years and it concluded that the forecasted values follow an upward pattern in the coming years.

(Maity, B., \& Chatterjee, B., 2012).

Another researcher tried to anticipate Gross Domestic Product of Pakistan for time period of 2013-2020. It was found that the GDP is about to increase in the stated time period. (Zakai, M., 2014).

A group of researchers used two model groups ARIMA and VAR to forecast GDP (country: Albania). Findings of the study stated that the group of VAR model provides improved results on forecasting of GDP rather than ARIMA model.(Shahini, L., \& Haderi, S., 2013).

The study conducted with use of three models ARIMA, VAR, AR(1) to anticipate per capita GDP of five regions of Sweden for time period of 1993-2009 found that all three models were effective for forecasting per capita GDP in later years. (Zhang, H., \& Rudholm, N., 2013).

While anticipating GDP growth in Bangladesh, a study applied ARIMA (P, I, Q) models and came to a smoothing way to forecast the GDP growth rate. Findings revealed that GDP growth rate of Bangladesh is rising and will continue to grow in the future. (Voumik, L. C., Rahman, M. M., Hossain, M. S., \& Rahman, M., 2019). An investigation was conducted using ARIMA model to forecast the GDP of Kenya. Short-run forecasts obtained were found to indicate an increase in Kenyan GDP level. (Wabomba, M. S., Mutwiri, M. P., \& Mungai, F., 2016).

A study focused on construction a time series model that was utilized to forecast the gross domestic product of China up to the first quarter of 2009. Researchers found that the forecasted value of GDP of the 1st quarter of 2009 was 71054.8 hundred million Yuan; the value was compared with the observed value:68745 hundred million Yuan . The researchers got $\operatorname{ARIMA}(4,1,0)$, which they applied for forecasting purposes. (Lu, Y., \& He, C., 2009).

US GDP time series was examined the for the quarterly, time period: 1970 to 1991. US GDP was found to be non-stationary on the basis of ACF and PACF. After making the first difference, it was stationary. Four-step Box-Jenkins (BJ) or ARIMA methodology was also applied by the researcher. The steps are estimation, identification, diagnostic checking and predicting the US GDP data. (Gujarati, D. N., 2003). 
Considering a time frame from 1996-2003, a research was conducted to study the economic and environmental trend. The researcher scrutinized the stationarity of time series data and exemplified that data were nonstationary. ARIMA model was constructed and anticipating was performed based on the model.

(Ahmed, H. U., 1998).

\section{Objective}

This paper imparts at predicting the annual GDP growth of Bangladesh for next couple of years considering the application of an apropos ARIMA (Autoregressive Integrated Moving Average) model consisting of three parameters such as $\mathrm{p}, \mathrm{r}$ and q applied to determine the Autoregressive (AR) order, differencing (I) order and Moving Average (MA) order respectively.

\section{Data and Methods}

Preparing this paper requires secondary data on annual GDP growth of Bangladesh between 1961 and 2019 so that the total sample size is 59 collected from World Bank Data stream. We have adopted Box-Jenkins (BJ) approach to construct the appropriate ARIMA models depending on three parameters considering the philosophy let the data speak themselves by investigating the probabilistic or stochastic properties of economic time series (here growth rate of GDP) on their own way. Unlike the regression models where $\mathrm{Y}_{\mathrm{t}}$ is explained by $\mathrm{K}$ regressors such as $\mathrm{X}_{1}, \mathrm{X}_{2}, \mathrm{X}_{3} \ldots \ldots \mathrm{X}_{\mathrm{k}}$ the $\mathrm{BJ}$-type time series (such as Growth rate of GDP of Bangladesh) models allow $Y_{t}$ to be regressed by past or lagged values of $Y$ (GDP growth rate) itself and stochastic error terms as described below:

\subsection{Autoregressive (AR) Process}

An autoregressive process for our time series data will be constructed by the model depicted in following equations:

$$
\left(G D P_{t}-\delta\right)=\alpha_{1}\left(G D P_{t-1}-\delta\right)+u_{t}
$$

where $\delta=$ is the mean of GDP growth and $\mathrm{u}_{\mathrm{t}}$ is an uncorrelated random error term with zero mean and constant variance followed by $\sigma^{2}$. Then, we can say that $\mathrm{GDP}_{t}$ follows a First-order autoregressive or $\mathbf{A R ( 1 )}$ stochastic process. In addition, the value of GDP growth at current period followed by time t depends on its value in the previous time period and a random error term provided that GDP growth values are expressed as deviations from their mean value. If we consider the following model presented under equation number 2 , we can say that $\mathrm{GDP}_{t}$ follows a secondorder autoregressive or $\mathbf{A R}(2)$ stochastic process which means the value of GDP growth at time $t$ depends on its value in the previous two time periods with a random error term provided that GDP growth values are expressed as deviations from their mean value 


$$
\left(G D P_{t}-\delta\right)=\alpha_{1}\left(G D P_{t-1}-\delta\right)+\alpha_{2}\left(G D P_{t-2}-\delta\right)+u_{t}
$$

Similarly, if we consider the following model presented under equation number 3, we can deduce that GDP ${ }_{t}$ follows a $\mathbf{p}^{\text {th }}$-order autoregressive or $\mathbf{A R}(\mathbf{p})$ stochastic process:

$$
\left(G D P_{t}-\delta\right)=\alpha_{1}\left(G D P_{t-1}-\delta\right)+\alpha_{2}\left(G D P_{t-2}-\delta\right)+\cdots+\alpha_{p}\left(G D P_{t-p}-\delta\right)+u_{t}
$$

\subsection{Moving Average (MA) Process}

The AR process presented in the earlier segment is not the only strategy for generating GDP growth rate at time t. Now, we have to consider another equation to construct a model that represents GDP growth as follows:

$$
G D P_{t}=\mu+\beta_{0} u_{t}+\beta_{1} u_{t-1}
$$

Where, $\mu$ is constant and $u_{t}$ is stochastic error term. Here GDP growth at time $t$ is equal to a constant plus a moving average of the current as well as past error terms. So, we can say that GDP growth in the above equation follows First-order moving average or MA(1) process. If GDP growth follows the equation presented below under equation number 5, we can say that it will follow an MA(2) process as mentioned below:

$$
G D P_{t}=\mu+\beta_{0} u_{t}+\beta_{1} u_{t-1}+\beta_{2} u_{t-2}
$$

More precisely, If we consider the following model presented under equation number 6 , we can say that $\mathrm{GDP}_{\mathrm{t}}$ follows a $\mathbf{q}^{\text {th }}$-order moving average or $\mathbf{M A}(\mathbf{q})$ stochastic process:

$$
G D P_{t}=\mu+\beta_{0} u_{t}+\beta_{1} u_{t-1}+\beta_{2} u_{t-2}+\cdots+\beta_{q} u_{t-q}
$$

\subsection{Autoregressive Moving Average (ARMA) Process}

If we assume that our GDP growth has both characteristics of AR (p) and MA (q) process, we can construct an ARMA $(1,1)$ standing for Autoregressive Moving Average model considering AR(1) and MA(1) process as presented below:

$G D P_{t}=\theta+\alpha_{1} G D P_{t-1}+\beta_{0} u_{t}+\beta_{1} u_{t-1}$

Where, $\theta$ represents a constant term followed by one autoregressive and one moving average term. Usually, An ARMA ( $\mathrm{p}, \mathrm{q})$ process follows $\mathrm{p}$ autoregressive and $\mathrm{q}$ moving average terms.

\subsection{Autoregressive Integrated Moving Average (ARIMA) Process}

The earlier time series models we have discussed so far are based on the assumption that time series data set (here annual GDP growth rate) follows stationary in sense 
showing the mean and variance for the said time series data set are constant and its covariance is time-invariant. In contrast, many economic time series are nonstationary that is they are integrated of specific order. If a time series is integrated of order 1, say I(1), its first differences are I(0), that is, stationary. Similarly, if a time series is I(2), its second difference is $\mathrm{I}(0)$ followed by stationary. So, if a time series is $\mathrm{I}(\mathrm{r})$, after differencing it $\mathrm{r}$ times, we can obtain $\mathrm{I}(0)$ showing stationary series. Therefore, if we have to estimate difference a time series data with $r$ times to make it stationary and thereby apply ARMA (p,q) model to it, we can define the original time series is ARIMA (p,r,q) with three parameters that is, it is an autoregressive integrated moving average time series where parameter $\mathrm{p}$ stands for number of autoregressive terms, $r$ stands for number of times the data series has to be differenced before it comes stationary and $\mathrm{q}$ stands for number of moving average terms as presented below as per equation number 8:

$$
\Delta G D P_{t}=\theta+\alpha_{1} \Delta G D P_{t-1} \ldots+\alpha_{p}\left(\Delta G D P_{t-p}\right)+u_{t}+\beta_{1} u_{t-1}+\cdots+\beta_{q} u_{t-q}
$$

where $\Delta \mathrm{GDP}_{\mathrm{t}}=\mathrm{GDP}_{\mathrm{t}}-\mathrm{GDP}_{\mathrm{t}-1}$ and if parameter $\mathrm{p}=0$ and $\mathrm{q}=0$, then the model becomes a stochastic walk model classified as ARIMA $(0,1,0)$ model.

We have adopted Box-Jenkins (BJ) approach consisting of following steps to select and implement the appropriate ARIMA $(\mathrm{p}, \mathrm{r}, \mathrm{q})$ model to forecast the annual GDP growth rate of Bangladesh for next couple of years:

\subsubsection{Identification}

In order to select the appropriate model, we have to make sure that the aforesaid time series data must be stationary in nature by plotting the ACF (Autocorrelation Function), PACF (Partial Autocorrelation Function) of the variable, say GDP growth rate, in level form. In addition, we can also check the stationary by applying Dicky-Fuller test of unit root rejecting a null hypothesis of presence of nonstationary in dataset. If we have been failed to reject null hypothesis as per the estimated outcome of Dicky-fuller test, the data series is said to be non-stationary and hence we have to follow the same approach after taking the $1^{\text {st }}$ difference of the said data series and then check the stationary by plotting the ACF and PACF of the $1^{\text {st }}$ difference of data series or applying Dicky-fuller unit root test on the $1^{\text {st }}$ difference of the data series of said variable (here is annual GDP growth). This will assist us to identify which autoregressive and moving average component should be applied in the ARIMA model.

\subsubsection{Estimation}

After Identification of the ARIMA model considering three parameters, we have to estimate the coefficients using computation algorithms that best fit the selected ARIMA model depending on either maximum likelihood estimator or non-linear least square estimator. 


\subsubsection{Diagnostic}

Before diagnostic check of the appropriate ARIMA (p,r,q) model, we have to execute test of goodness-of-fit among the ARIMA models estimated with different forms of the three parameters such as ARIMA $(1,0,1)$, $\operatorname{ARIMA}(1,1,1)$, $\operatorname{ARIMA}(1,2,1), \operatorname{ARIMA}(2,2,1), \operatorname{ARIMA}(1,2,2)$ or ARIMA $(2,2,2)$ models using the AIC or BIC index value estimated for all ARIMA models with respective parameters. After selecting the best ARIMA model among these different models, we have to conduct diagnostic check for the best fitted ARIMA model by plotting the ACF, PACF or executing Unit root test of the residual estimated with the selected ARIMA model.

\subsubsection{Forecasting}

Once the selected ARIMA (p,r,q) model confirms to the specifications of a stationary univariate process considering the outcome of ACF, PACF or Unit root test of residual, we can proceed for forecasting the annual GDP growth of Bangladesh for next couple of years using this model.

\section{Data Analysis and Discussion}

According to the preliminary analysis of annual GDP growth data series plotted by two way time line depicted in Figure 1, visual inspection of time plot navigates that aforesaid data series is stationary in level form. In addition, the same consequence followed by stationary behavior is also reflected in the correlogram of annual GDP growth data series confirmed by the ACF (autocorrelation function) and PACF (partial autocorrelation function) plots depicted in Figure 2 and 3 respectively followed by $\mathrm{p}$-values of Q-test mentioned under Table 1 showing all $\mathrm{p}$-values are more than 0.05 and thereby suggesting a stationary behavior of annual GDP growth of Bangladesh since 1961. 


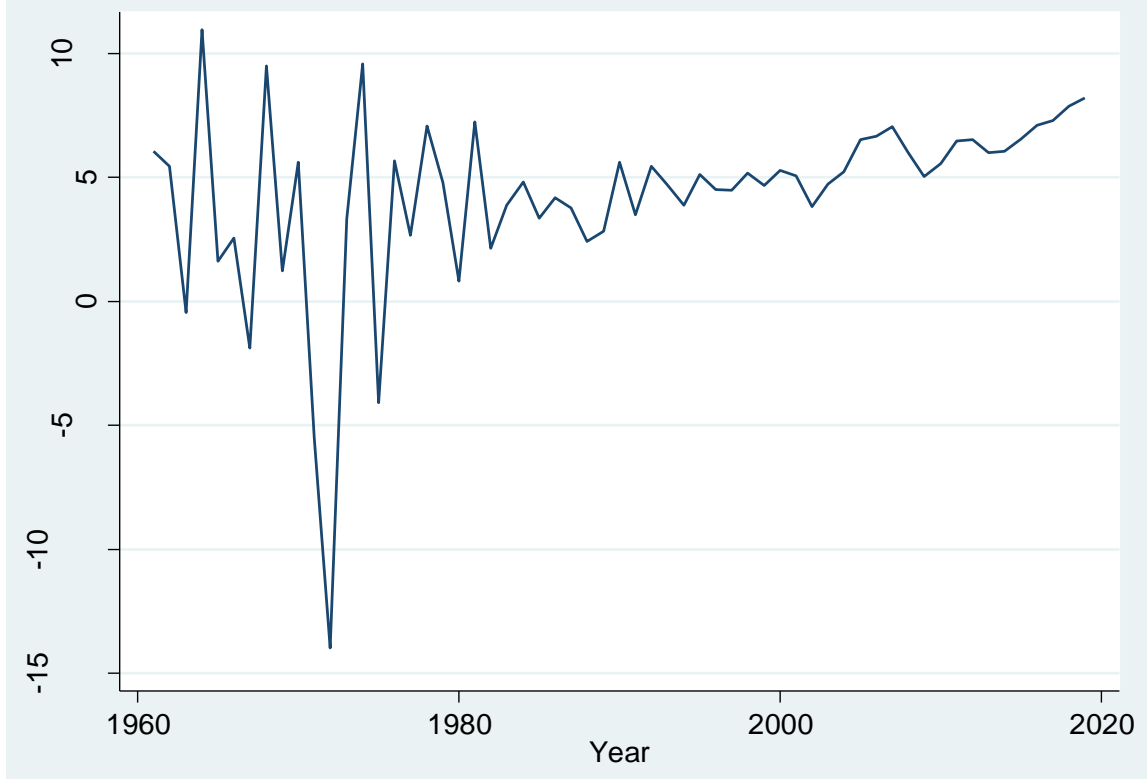

Figure 1: Time series plot for annual GDP growth of Bangladesh since 1961 
Table 1: Correlogram of annual GDP growth dataset of Bangladesh since 1961

- corrgram gdpgrowthannual

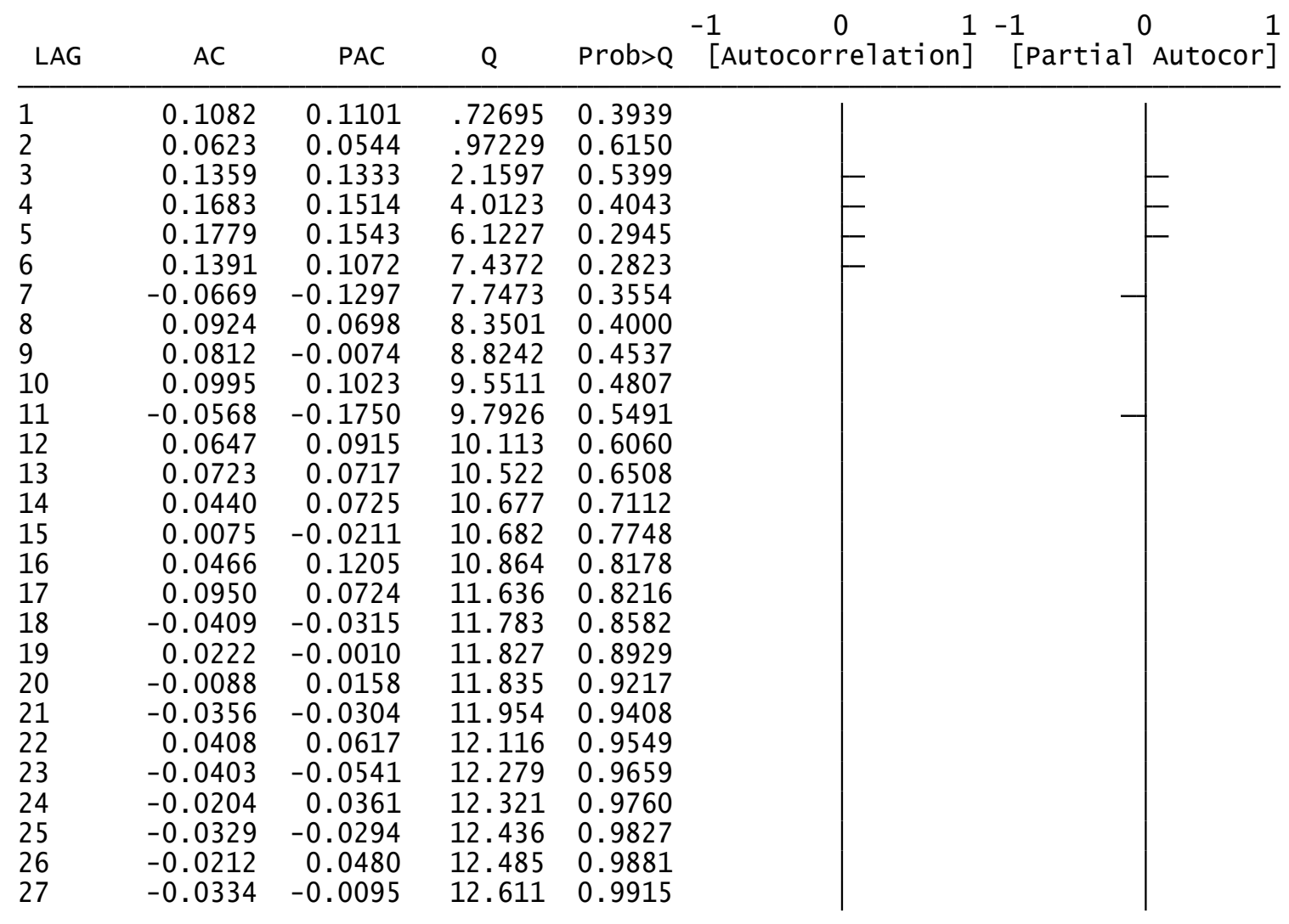

Source: Figure developed by STATA 12.0 


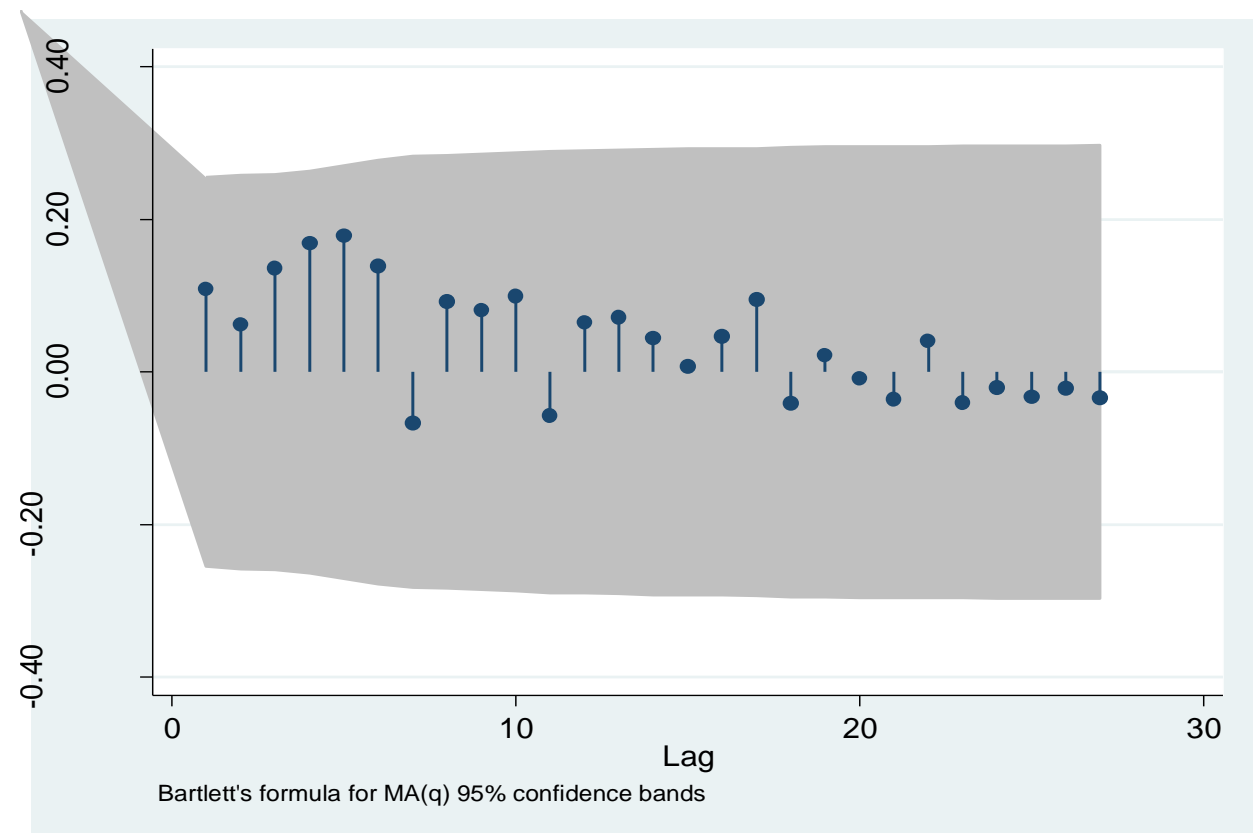

Figure 2: ACF (autocorrelation function) plot for annual GDP growth of Bangladesh since 1961

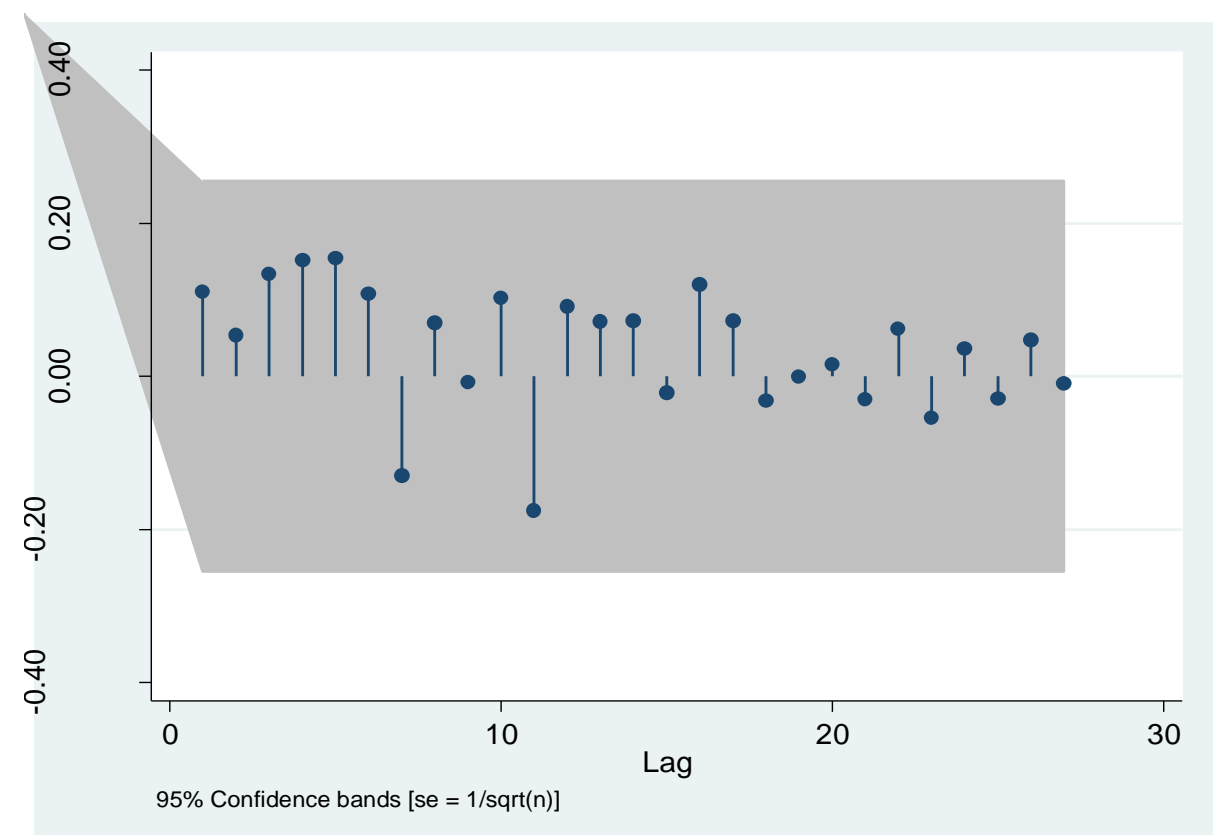

Figure 3: PACF (partial autocorrelation function) plot for annual GDP growth of Bangladesh since 1961 


\subsection{Unit root test of GDP growth}

The aforesaid data series has been tested to ensure the stationary so that the mean, variance and covariance will remain constant followed by performing Dickey-fuller test for unit root where the null hypothesis of the presence of non-stationary in the dataset of annual GDP growth has been rejected and concluded that this data series is stationary as per the output mentioned below under Table 1

Table 2: Output of Dickey-Fuller test for unit root of GDP growth dataset

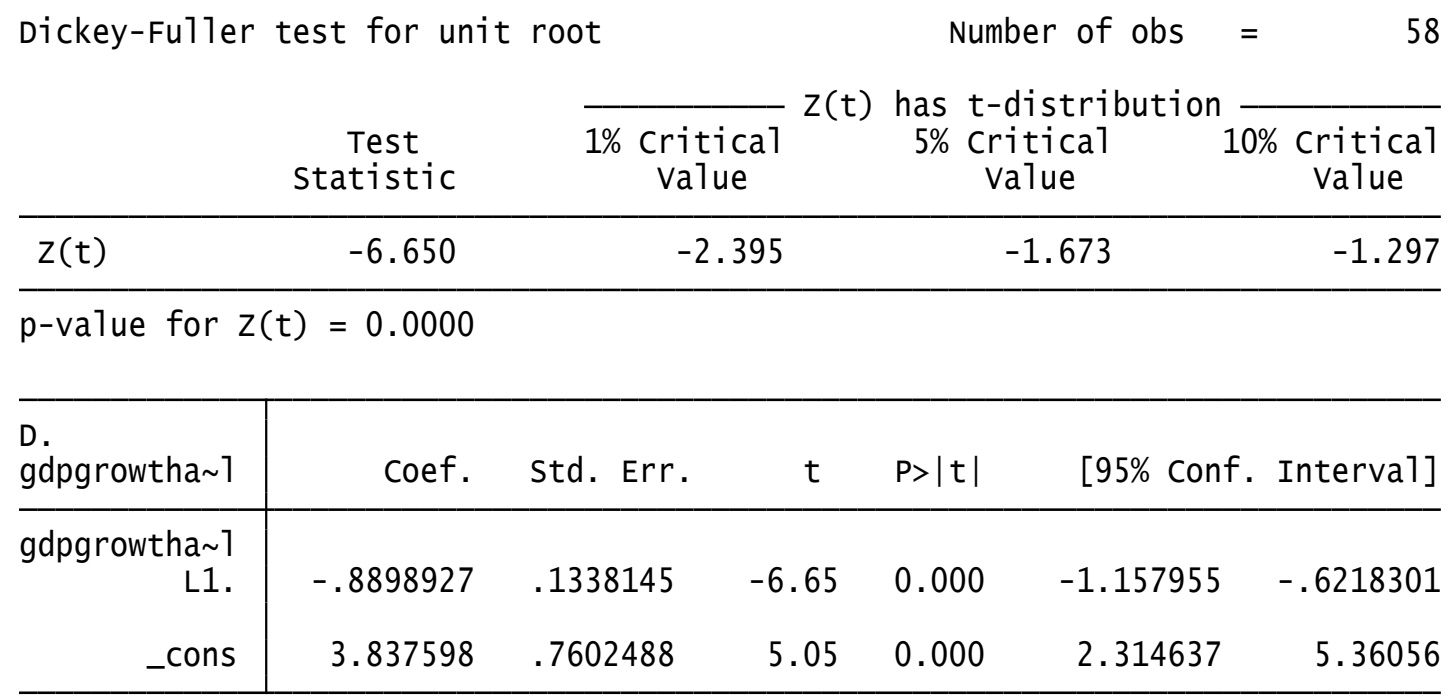

Source: output estimated by STATA12.0

\subsection{Formation of appropriate ARIMA model}

Once the data series of annual GDP growth has been found stationary, we have to proceed for developing an appropriate ARIMA model with respect to the order of three parameters such as $\mathrm{p}, \mathrm{r}$ and $\mathrm{q}$ followed by AR (autoregressive), I (Integrated) and MA (Moving average) process respectively. According to the ACF and PACF plots depicted earlier under Figure 2 and 3 respectively, we expect that the proper values of these three parameters $\mathrm{p}, \mathrm{r}$ and $\mathrm{q}$ are $\mathrm{p}=1, \mathrm{r}=0$ and $\mathrm{q}=1$ navigated by ARIMA $(1,0,1)$ model corresponding to ARIMA (p,r,q) model used to predict the annual GDP growth of Bangladesh for next couple of years. In other words, Modeling results of an ARIMA $(1,0,1)$ process has been presented in following Table 3 showing the estimated results using MLE approach where the estimated coefficient of $\mathrm{AR}(1)$ and $\mathrm{MA}(1)$ along with the constant are found statistically significant at 5\% level. Moreover, this model also reveals the joint or overall significance at $0.1 \%$ level according to the value of chi-square statistic as mentioned below: 
Table 3: Output of ARIMA $(1,0,1)$ model to predict annual GDP growth of Bangladesh

ARIMA regression

Sample: $1961-2019$

Log likelihood $=-161.6497$

$\begin{array}{llr}\text { Number of obs } & = & 59 \\ \text { Wald chi2(2) } & = & 22.61 \\ \text { Prob }>\text { chi2 } & = & 0.0000\end{array}$

\begin{tabular}{|c|c|c|c|c|c|c|}
\hline gdpgrowtha 1 & Coef. & $\begin{array}{c}\text { OPG } \\
\text { Std. Err. }\end{array}$ & z & $P>|z|$ & [95\% Conf. & Interval] \\
\hline $\begin{array}{r}\text { gdpgrowtha 1 } \\
\text { _cons }\end{array}$ & 4.340101 & .7216499 & 6.01 & 0.000 & 2.925693 & 5.754509 \\
\hline $\begin{array}{l}\text { ar } \\
\text { L1. }\end{array}$ & -.9696866 & 4418938 & -2.19 & 0.028 & -1.835783 & -.1035907 \\
\hline $\begin{array}{l}\text { ma } \\
\mathrm{L} 1 .\end{array}$ & .9587306 & .4860795 & 1.97 & 0.049 & .0060323 & 1.911429 \\
\hline /sigma & 3.7461 & .282854 & 13.24 & 0.000 & 3.191717 & 4.300484 \\
\hline
\end{tabular}

Source: Output developed from STATA 12.0

Moreover, we have also estimated the other ARIMA (p,r,q) models to test the goodness of fit of the aforesaid model comparing with the estimated output of other models with respect to the order of these three parameters as revealed below:

Table 4: ARIMA (p,r,q) orders of several models

Source: Authors' self-contribution

\begin{tabular}{|c|c|}
\hline Model number & ARIMA (p,r,q) order \\
\hline ARIMA_Model1 & ARIMA $(1,0,1)$ \\
\hline ARIMA_Model2 & ARIMA $(1,1,1)$ \\
\hline ARIMA_Model3 & ARIMA $(1,2,1)$ \\
\hline ARIMA_Model4 & ARIMA $(2,1,2)$ \\
\hline ARIMA_Model5 & ARIMA $(2,2,1)$ \\
\hline ARIMA_Model6 & ARIMA $(2,2,2)$ \\
\hline
\end{tabular}

The following Table shows the estimated coefficients along with the constant under different ARIMA models with respect to $\mathrm{p}, \mathrm{r}$ and $\mathrm{q}$ orders at $0.1 \%, 1 \%$ and $5 \%$ level of significance to derive the best model for forecasting the annual growth of GDP of Bangladesh. Among these models, only ARIMA_Model1 with order of ARIMA $(1,0,1)$ process is individually as well as statistically significant at chosen level of significance for all of its estimated coefficients with constant corresponding to AR (1) and MA (1) process respectively. 
None of the other models ranging from ARIMA_Model2 to ARIMA_Model6 has been found statistically sound comparing to ARIMA_Model1 as mentioned below:

Table 5: Comparison among the estimates of different ARIMA (p,r,q) models

\begin{tabular}{|c|c|c|c|c|c|c|}
\hline Variable & ARIMA_Model1 & ARIMA_Mode12 & ARIMA_Mode13 & ARIMA_Model4 & ARIMA_Mode15 & ARIMA_Mode16 \\
\hline $\begin{array}{r}\text { gdpgrowtha } 1 \\
\text { _cons }\end{array}$ & $4.340101 \% * *$ & .08539382 & .00991148 & .08617986 & .00770581 & .00771744 \\
\hline $\begin{array}{l}\mathrm{ar} \\
\mathrm{L} 1 . \\
\mathrm{L} 2 .\end{array}$ & $-.96968661^{*}$ & -.03425666 & $-.46306012 * \cdots *$ & $\begin{array}{r}-.09379444 \\
-.0964125\end{array}$ & 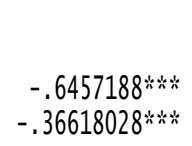 & $\begin{array}{l}-.65251928 * \\
-.36767162 * *\end{array}$ \\
\hline $\begin{array}{l}\text { ma } \\
\mathrm{L} 1 . \\
\mathrm{L} 2 .\end{array}$ & $.95873061^{*}$ & $-.9999981 * * *$ & $-.99999848 * \mathrm{w*}$ & $\begin{array}{l}-.94892824 \\
-.05107485\end{array}$ & -.99998863 & $\begin{array}{r}107.2658 \\
-108.25977\end{array}$ \\
\hline $\begin{array}{l}\text { sigma } \\
\end{array}$ _cons & $3.7461004 \%$ & 3.4820712 & 4.4393886 & 3.4613434 & 4.1000802 & .03791132 \\
\hline $\begin{array}{r}\text { Statistics } \\
\mathrm{N} \\
\text { chi2 } \\
\text { sigma }\end{array}$ & $\begin{array}{r}59 \\
22.608868 \\
3.7461004\end{array}$ & $\begin{array}{r}58 \\
101.11079 \\
3.4820712\end{array}$ & $\begin{array}{r}57 \\
108.63593 \\
4.4393886\end{array}$ & $\begin{array}{r}58 \\
84.868754 \\
3.4613434\end{array}$ & $\begin{array}{r}57 \\
86.853296 \\
4.1000802\end{array}$ & $\begin{array}{r}57 \\
91.578777 \\
.03791132\end{array}$ \\
\hline
\end{tabular}

Source: Output developed by STATA12.0

\subsection{Selection of appropriate ARIMA (p,r,q) models using AIC and BIC Index}

In addition, we have also performed the model specification test among all these estimated ARIMA (p,r,q) models considering the value of AIC standing for Akaike Information Criterion and BIC standing for Bayesian Information Criterion of respective models as revealed below:

Table 7: AIC and BIC value of all estimated ARIMA (p,r,q) Models

\begin{tabular}{|l|l|l|}
\hline $\begin{array}{l}\text { ARIMA Models with order } \\
\text { (p,r,q) }\end{array}$ & $\begin{array}{l}\text { AIC } \\
\text { value }\end{array}$ & $\begin{array}{l}\text { BIC } \\
\text { value }\end{array}$ \\
\hline ARIMA (1,0,1) Model & 319.472 & 325.6534 \\
\hline ARIMA (1,1,1) Model & 331.2994 & 339.6096 \\
\hline ARIMA (1,2,1) Model & 342.7291 & 348.8582 \\
\hline ARIMA (2,1,2) Model & 322.9683 & 333.2705 \\
\hline ARIMA (2,2,1) Model & 338.5849 & 348.8002 \\
\hline ARIMA (2,2,2) Model & 340.6949 & 352.9532 \\
\hline
\end{tabular}

Source: Authors' self-contribution 
According to the estimated result of AIC and BIC value corresponding to each ARIMA (p,r,q) models mentioned in above table, the first model navigated by ARIMA $(1,0,1)$ is the best suitable model for prediction the annual GDP growth of Bangladesh as the AIC and BIC value of the corresponding model shows the lowest value compared to the estimated AIC and BIC values of other models. As a consequence, we have adopted the appropriate ARIMA $(1,0,1)$ model with respect to the order of $\mathrm{p}=1, \mathrm{r}=0$ and $\mathrm{q}=1$ as shown below:

$$
G D P_{t}=4.34-0.9696\left(G D P_{t-1}\right)+0.9587\left(u_{t-1}\right)+u_{t}
$$

where, $G \mathrm{GDP}_{\mathrm{t}}=$ Estimated GDP growth for respective year, $\mathrm{GDP}_{(\mathrm{t}-1)}=$ one year lagged annual GDP growth rate $\mathrm{u}_{\mathrm{t}}=$ error term of the model for respective year $\mathrm{u}_{(\mathrm{t}-1)}=$ one year lagged error term of the model

\subsection{Diagnostic check of the selected ARIMA $(1,0,1)$ model}

According to the Box-Jenkins approach, the validity of the aforesaid ARIMA $(1,0,1)$ model can be ensured by applying diagnostic test on the stationary of the residuals estimated by the said ARIMA model. The preliminary analysis consists of plotting the estimated one-step residuals against time depicted in Figure 4 shows stationary in residuals followed by the process of de-trending showing same output reflected in ACF and PACF plot of residuals depicted under Figure 5 and Figure 6 respectively as per the correlogram Table of residuals enclosed in the Appendix of this paper mentioned below:

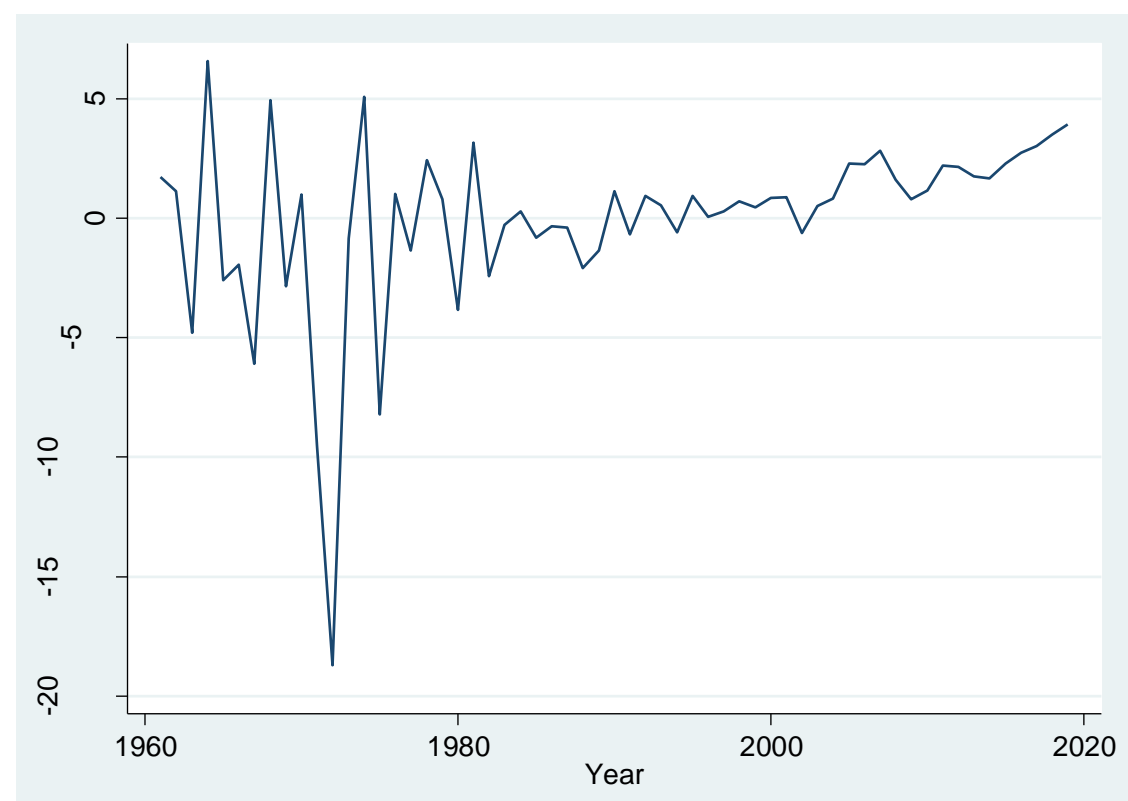

Figure 4: Time series plot for ARIMA(1,0,1) estimated residuals since 1961 


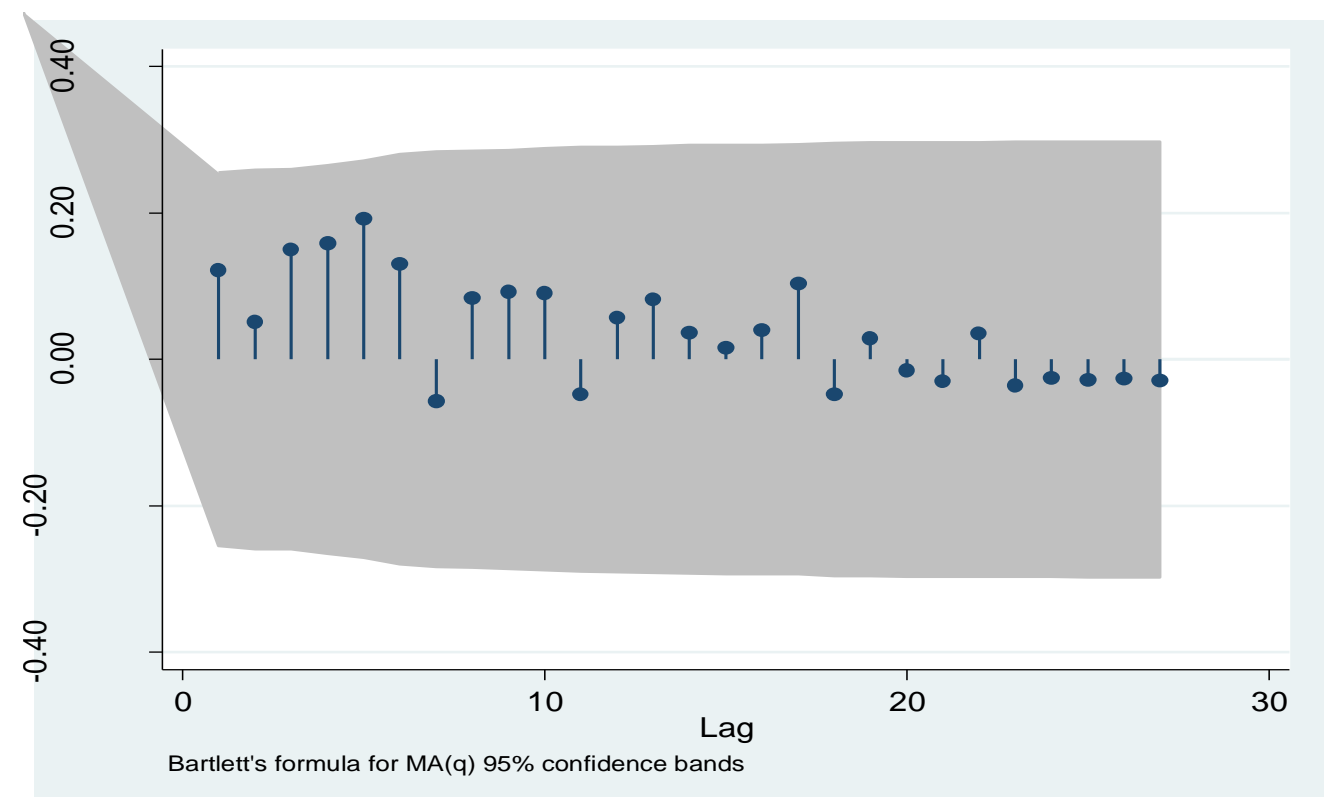

Figure 5: ACF plot for estimated ARIMA $(1,0,1)$ residuals

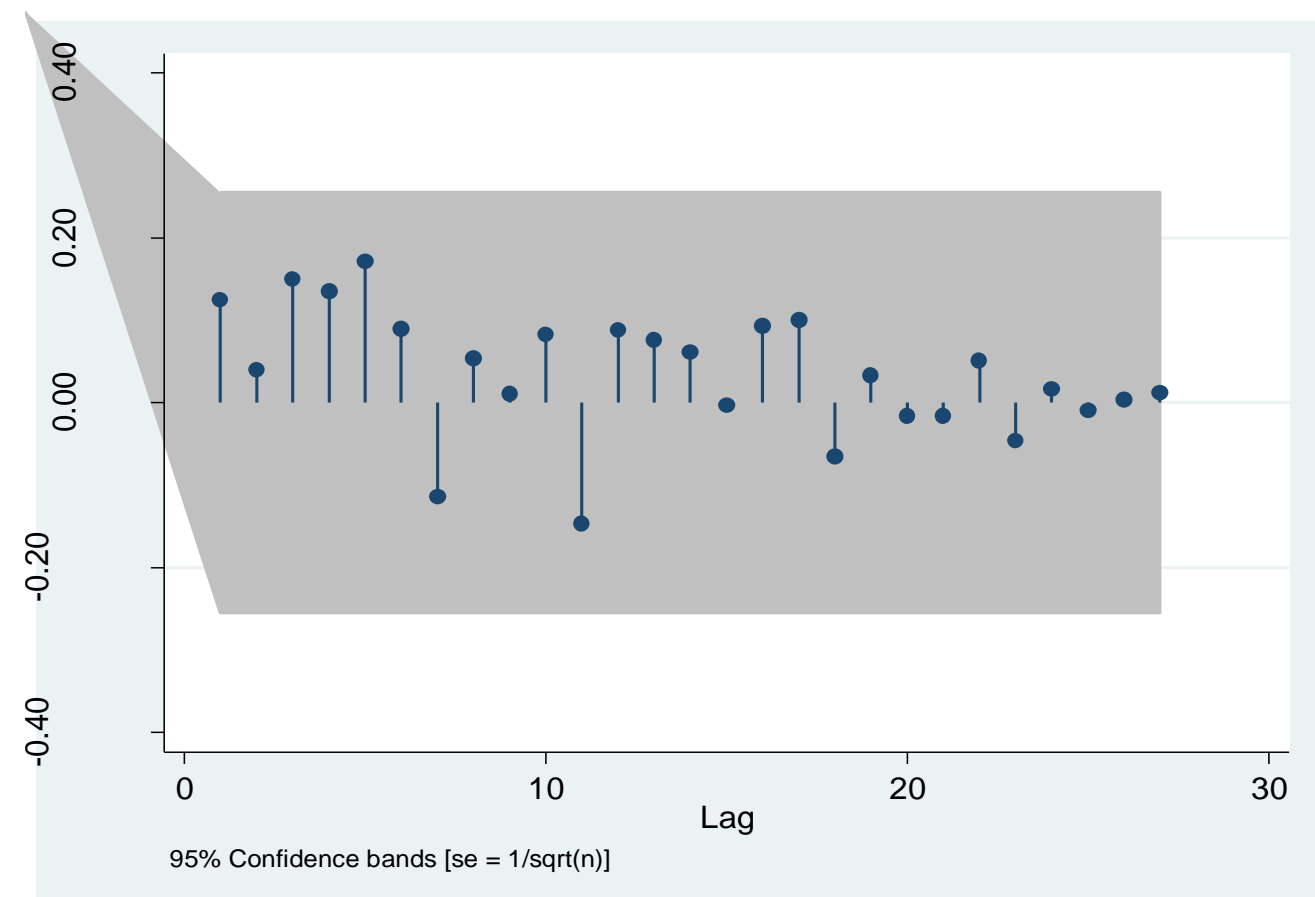

Figure 6: PACF plot for estimated ARIMA $(1,0,1)$ residuals 


\subsection{Unit root test of residual}

To ensure the stationary in estimated residuals so that the mean, variance and covariance will remain constant followed by performing Dickey-fuller test for unit root where the null hypothesis of the presence of non-stationary in the dataset of residuals has been rejected at $0.1 \%$ level of significance and concluded that this data series residuals is stationary as per the output mentioned below under Table 8:

Table 8: Output of Dickey-Fuller test for unit root of estimated residuals

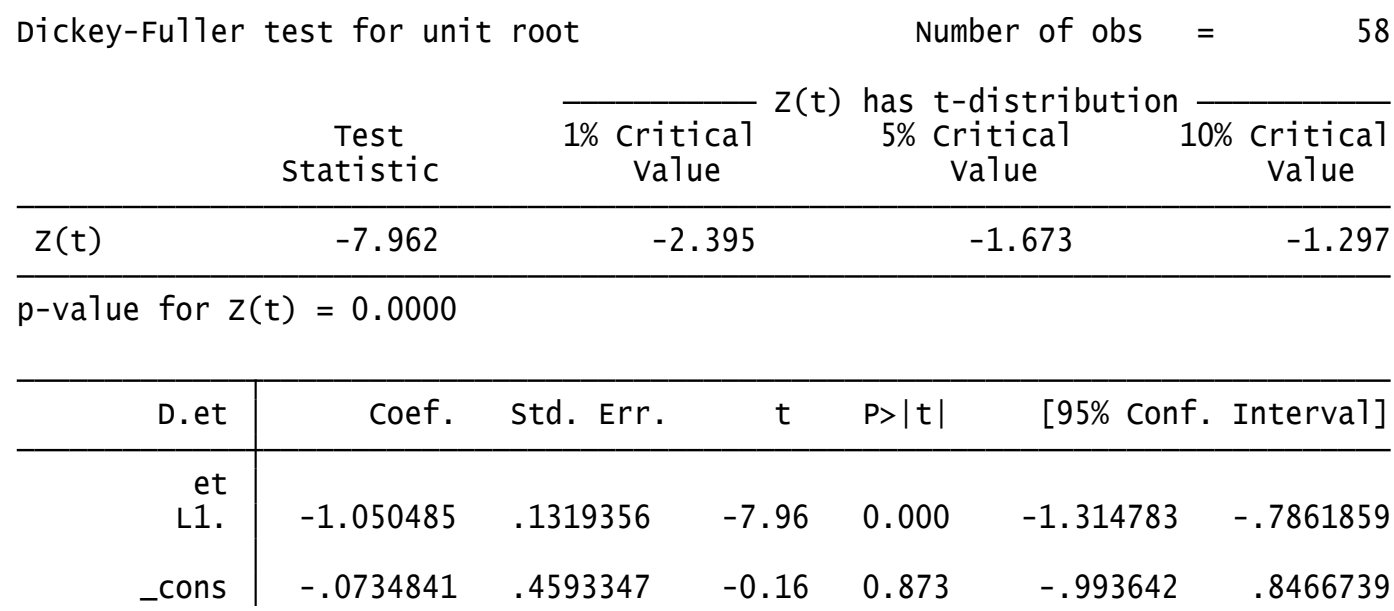

Source: Output developed by STATA 12.0

\subsection{Predicted annual GDP growth of Bangladesh using ARIMA (1,0,1) Model}

Using the ARIMA $(1,0,1)$ model tailored to the GDP growth data set, we can apply the equation number 9 to forecast the values of annual GDP growth in Bangladesh for next Five years out of sample ranging from 2020 to 2024 presented in the following table:

Table 9: Forecasted Values of GDP growth of BANGLADESH using ARIMA $(1,0,1)$ model

\begin{tabular}{|c|c|}
\hline Year (Out of Sample) & Forecasted GDP growth (in \%) \\
\hline 2020 & 4.36461 \\
\hline 2021 & 4.316335 \\
\hline 2022 & 4.363146 \\
\hline 2023 & 4.317754 \\
\hline 2024 & 4.36177 \\
\hline
\end{tabular}

Source: Authors' self-contribution based on output from STATA 12.0

The predicted values presented in the aforesaid Table reveal ups and down trend depending on the values of coefficients estimated earlier using ARIMA $(1,0,1)$ 
model provided that these are only forecasted value of GDP growth for next five years that may be dynamic considering the risk of adjustment in the economic operations along with continuity of macroeconomic regulations and policy implications to maintain stability in the economy amid outbreak of COVID-19 pandemic. However, If we continue plotting the predicted annual GDP growth of Bangladesh estimated by ARIMA $(1,0,1)$ model till 2039, the pattern of the forecasted data series follows stationary as depicted from following Figure:

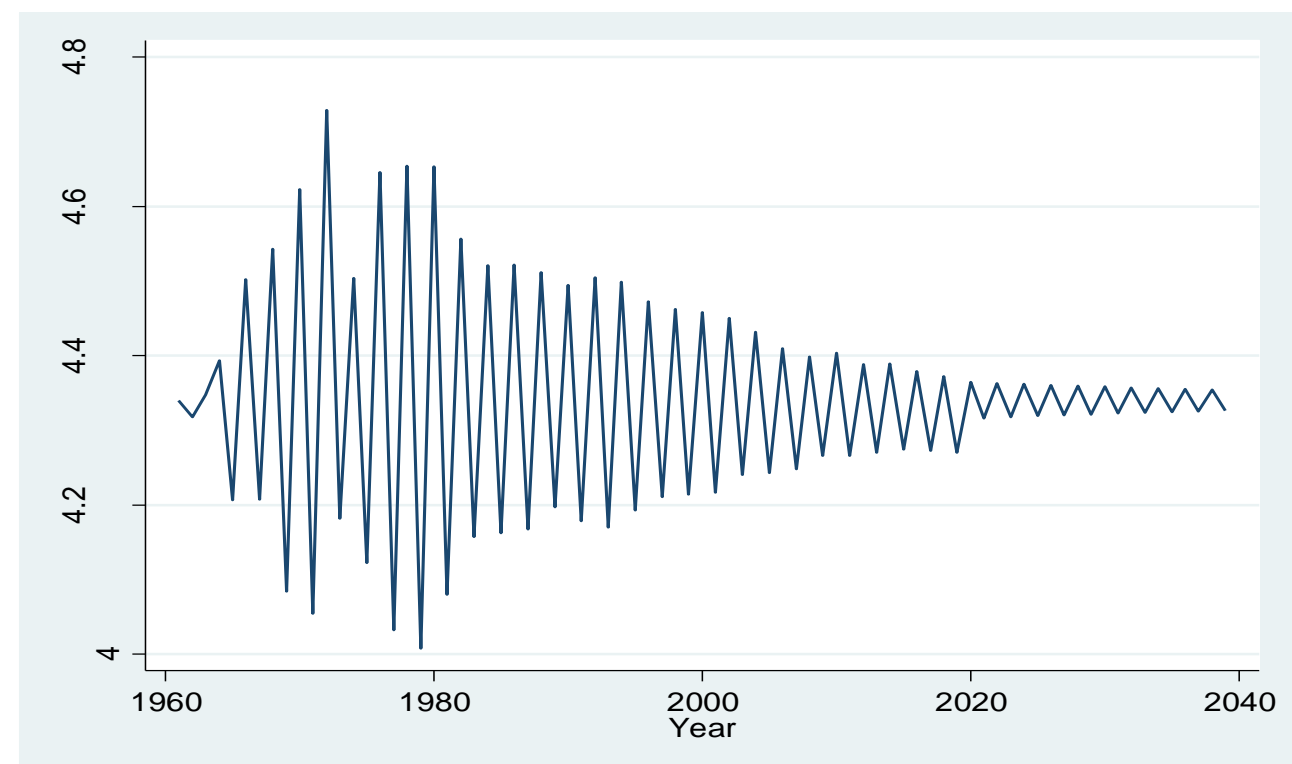

Figure 7: Predicted values of GDP growth estimated with ARIMA $(1,0,1)$ model till year 2039

Moreover, the report from World Bank predicts economic growth may be fallen in between 2 to 3\% for the fiscal year 2019-2020 amid impact of COVID-19 pandemic in Bangladesh instead of projected $8.2 \%$.

\section{Conclusion}

GDP is considered as an essential parameter of economic performance of a country. It can be addressed as a weighty element in case of setting up economic policies. Using an Autoregressive Integrated Moving Average (ARIMA) Model, we have tried to predict the economic growth measured with annual GDP growth of Bangladesh. We tried to predict the annual GDP growth of Bangladesh for next couple of years. For this we considered the application of an apropos ARIMA (Autoregressive Integrated Moving Average) model. Secondary data on annual GDP growth of Bangladesh between 1961 and 2019 have been used. To construct the appropriate ARIMA models, we have adopted Box-Jenkins (BJ) approach. Modeling results of an ARIMA $(1,0,1)$ process is revealing the estimated results 
using MLE approach where the estimated coefficient of AR(1) and MA(1) along with the constant is found statistically significant at $5 \%$ level. With the presentation of Table 9 we have shown the forecasted value of GDP growth for next five years that may be dynamic considering the risk of adjustment in the economic operations along with continuity of macroeconomic regulations and policy implications to maintain stability in the economy amid outbreak of COVID-19 pandemic. Instead of projected $8.2 \%$, economic growth may be fallen in between $2.5 \%$ to $4 \%$ for the fiscal year 2019-2020 amid impact of COVID-19 pandemic in Bangladesh. 


\section{References}

[1] Ahmed, H. U. (1998). Analysis of some selected economic and environmental time series of Bangladesh (Doctoral dissertation, PhD Thesis, Department of Statistics, Jahangirnagar University, Dhaka, Bangladesh).

[2] Bhuiyan, M. N. A., Ahmed, K. S., \& Jahan, R. (2008). Study on Modeling and Forecasting of the GDP of Manufacturing Industries in Bangladesh. Chiang Mai University Journal of Social Science and Humanities, 2(2), 143-157.

[3] Dritsaki, C. (2015). Forecasting real GDP rate through econometric models: an empirical study from Greece. Journal of International Business and Economics, 3(1), 13-19.

[4] Gujarati, D. N. (2003). Basic Econometrics. Fourth Edition. Singapura: McGraw-Hill.

[5] Lu, Y., \& He, C. (2009). Modeling and forecasting China's GDP data with time series models. Department of Economics and Society.

[6] Maity, B., \& Chatterjee, B. (2012). Forecasting GDP growth rates of India: An empirical study. International Journal of Economics and Management Sciences, 1(9), 52-58.

[7] Ning, Wei, BianKuan-jiang, and Yuan Zhi-fa. "Analysis and forecast of Shaanxi GDP based on the ARIMA Model." Asian Agricultural Research 2, no. 1812-2016-143365 (2010): 34-41.

[8] Shahini, L., \&Haderi, S. (2013). SHORT TERM ALBANIAN GDP FORECAST:" ONE QUARTER TO ONE YEAR AHEAD". European Scientific Journal, 9(34).

[9] Uwimana, A., Xiuchun, B., \& Shuguang, Z. (2018). Modeling and forecasting Africa's GDP with time series models. International Journal of Scientific and Research Publications, 8(4), 41-46.

[10] Voumik, L. C., Rahman, M. M., Hossain, M. S., \& Rahman, M. (2019). Forecasting GDP growth rates of Bangladesh: an empirical study. Indian Journal of Economics and Development, 7(7).

[11] Wabomba, M. S., Mutwiri, M. P., \& Mungai, F. (2016). Modeling and forecasting Kenyan GDP using autoregressive integrated moving average (arima) models. Science Journal of Applied Mathematics and Statistics, 4(2), 64-73.

[12] Zakai, M. (2014). A time series modeling on GDP of Pakistan. Journal of Contemporary Issues in Business Research, 3(4), 200-210.

[13] Zhang, H., \& Rudholm, N. (2013). Modeling and forecasting regional GDP in Sweden using autoregressive models. Dalama University. 


\section{APPENDIX:}

Table 10: Correlogram of residuals estimated by ARIMA $(1,0,1)$ model

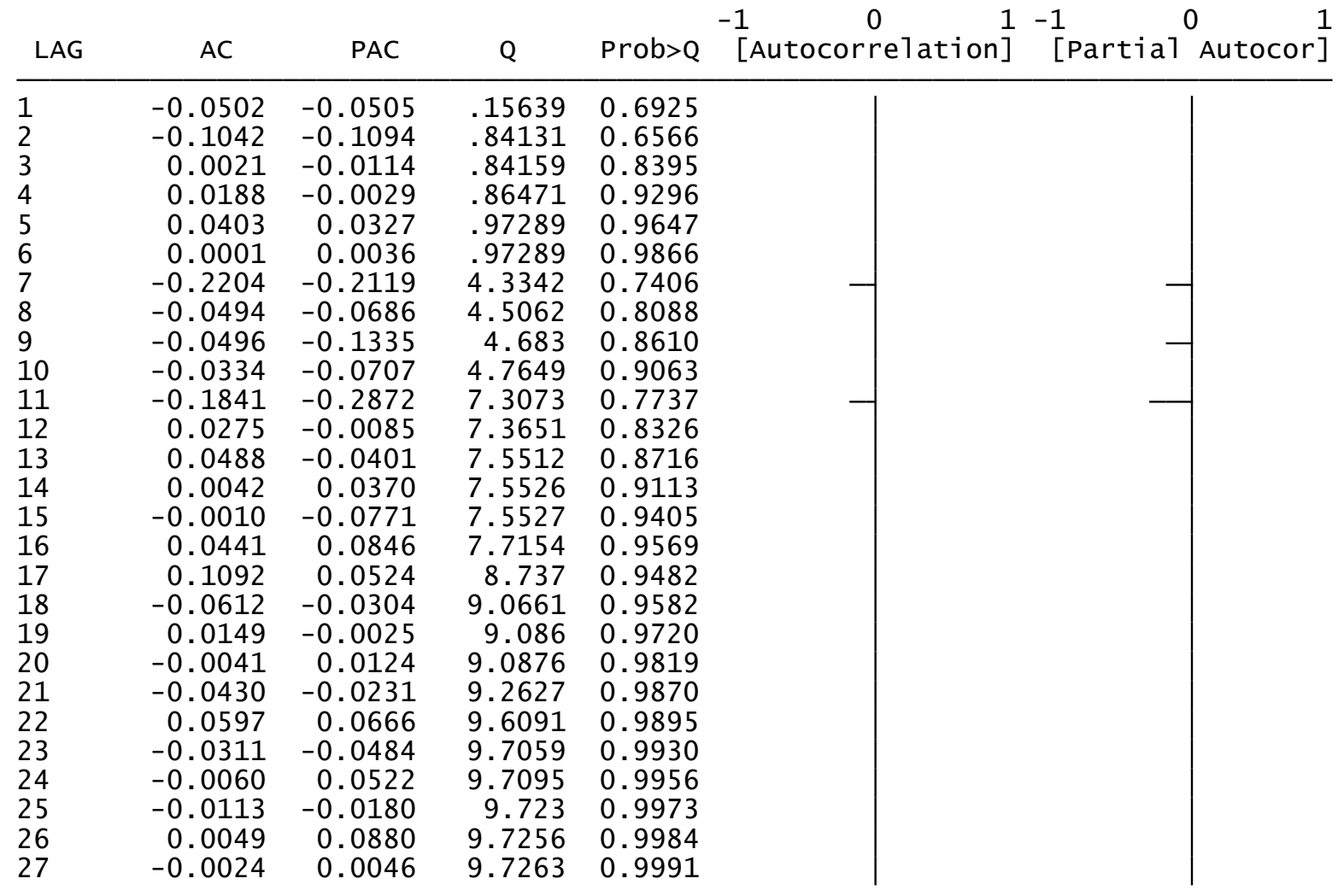

